\title{
A global registry for idiopathic pulmonary fibrosis: the time is now
}

\author{
Christopher J. Ryerson 1 , Tamera J. Corte ${ }^{2}$, Harold R. Collard ${ }^{3}$ and \\ Luca Richeldi ${ }^{4,5}$
}

\begin{abstract}
Affiliations: 'Dept of Medicine, University of British Columbia, Vancouver, BC, Canada. ${ }^{2}$ Dept of Respiratory Medicine, Royal Prince Alfred Hospital, University of Sydney, Sydney, Australia. ${ }^{3}$ Dept of Medicine, University of California San Francisco, San Francisco, CA, USA. ${ }^{4}$ Academic Unit of Clinical and Experimental Sciences, University of Southampton Faculty of Medicine, University Hospital Southampton, Southampton, UK. ${ }_{5}^{5}$ Southampton NIHR Respiratory Biomedical Research Unit, University Hospital Southampton, Southampton, UK.
\end{abstract}

Correspondence: Luca Richeldi, NIHR Southampton Respiratory Biomedical Research Unit, Southampton Centre for Biomedical Research, Level E, South Block, University Hospital Southampton, Tremona Road, Southampton, S016 6YD, UK. E-mail: L.Richeldidsoton.ac.uk

0 @ERSpublications

A global IPF registry would reshape the research landscape and generate unprecedented progress toward a cure for IPF http://ow.ly/vh14c

Idiopathic pulmonary fibrosis (IPF) is a chronic progressive interstitial lung disease (ILD) of unknown aetiology with a median survival of only 3 years [1]. As a rare and orphan disease, IPF is difficult to study even within specialised referral centres and regional collaborative networks [2]. Although some local and regional prospective IPF registries exist, they generally do not share methodology and are not easily combined.

A global IPF registry would facilitate a better understanding of disease biology and behaviour [3], as well as identification of regional variations in diagnostic and management patterns that will help establish best practices [4]. Moreover, a global IPF registry would create a network for more efficient and affordable clinical trial conduct [5-7], and provide a platform for collaboration among stakeholders (patients, caregivers, clinicians, researchers, professional and scientific societies, industry partners, and governments).

We believe it is time to actively develop a global registry for IPF patients. The disease and the patients who suffer from it cannot wait. We propose a 5 -year plan to achieve this goal (fig. 1).

\section{Create the network}

The first step in developing a global IPF registry is to identify capable, internationally acceptable sponsors to organise a global group of highly motivated IPF centres to serve as core members. A number of national advocacy groups and societal national organisations (e.g. the Pulmonary Fibrosis Foundation and the American Thoracic Society in the USA, and the British Lung Foundation and the British Thoracic Society in the UK) share many of the goals of a global IPF registry, and efforts to establish IPF networks have recently been undertaken in these and other countries. We believe that advocacy groups are best positioned to coordinate an international registry effort. They are the least constrained by regional considerations and biases, and as an advocate for patients they are in a unique position to balance input from all of the relevant stakeholders.

\section{Secure initial funding}

There are considerable costs associated with the development and management of a registry. A central electronic database, research coordination and data entry at each centre are necessary. If included,

Received: March 182014 | Accepted after revision: March 202014

Conflict of interest: Disclosures can be found alongside the online version of this article at erj.ersjournals.com 


\begin{tabular}{|c|c|c|}
\hline Objective & Key recommendations & Timeline \\
\hline Create the network & $\begin{array}{c}\text { Identify a sponsor and organise an international group of } \\
\text { highly motivated IPF centres }\end{array}$ & 6 months \\
\hline \multicolumn{3}{|c|}{15} \\
\hline Secure initial funding & Develop a business plan and approach interested sponsors & $12-18$ months \\
\hline \multicolumn{3}{|c|}{15} \\
\hline Define the objectives & $\begin{array}{c}\text { Collect input from all relevant stakeholders and develop an } \\
\text { executive structure to establish clear priorities }\end{array}$ & 6 months \\
\hline \multicolumn{3}{|c|}{15} \\
\hline Identify the content & Determine core data elements based on registry objectives & $12-18$ months \\
\hline \multicolumn{3}{|c|}{15} \\
\hline $\begin{array}{l}\text { Pilot and expand } \\
\text { the registry }\end{array}$ & $\begin{array}{c}\text { Utilise core sites to test registry logistics and identify } \\
\text { additional sites, and consider broadening the registry } \\
\text { to include other ILDs }\end{array}$ & 6 months \\
\hline
\end{tabular}

FIGURE 1 Major steps and the timeline for the development of a global idiopathic pulmonary fibrosis (IPF) registry. It is anticipated that some of these steps will overlap/occur simultaneously rather than occur sequentially. ILD: interstitial lung disease.

biospecimen procurement and storage adds significant expense. With focused objectives, feasible content and a solid business plan, we believe that funds can be secured to support a global registry effort. Advocacy groups, national organisations and industry sponsors will play a critical role early in this effort, with subsequent funding from government partners who will use the registry for research and administrative purposes.

\section{Define the objectives}

Successful registries need clearly defined and focused objectives. For example, a global IPF registry could identify geographic variability in patient characteristics and behaviour, or with how regional differences in practice patterns (including the use of approved drugs) impact on clinical outcomes. Specifying clear objectives early in the development process will provide focus, allowing distinction between essential and nonessential registry content. Defining the objectives would begin with collecting input from all stakeholders and creating an administrative structure to review this input and establish clear priorities.

\section{Identify the content}

Beyond demographics and outcome, there is no general consensus on what data should be collected; this should be dictated by the objectives identified. The balance between benefits and costs (both financial and logistical) need to be considered for each potential data element. Table 1 summarises what we believe to be core content of a global IPF registry, regardless of the defined objectives. Biospecimens linked to clinical data are a valuable but costly and labour intensive addition. The inclusion of biospecimens in the initial registry will need to be carefully considered and need to be based on the registry's stated objectives. Registry documentation of local biospecimen collection and banking at participating sites might be an initial approach.

\section{Pilot and expand the registry}

The operational details of a registry can be complex and will probably vary among sites. For example, privacy policies will differ between countries. Given the challenges associated with the initiation phase of a large multi-centred registry, we suggest a testing phase at core sites representing major geographical areas to identify problems and test procedures before full expansion to additional sites. These pilot sites could be selected from centres that have local registry infrastructure and personnel already in place.

Expansion of this registry to additional sites should be a priority, but must be carefully planned and regulated to ensure that data quality remains high and costs controlled. This will require close oversight from the registry's governance. The number and locations of sites will be influenced by local factors, registry objectives and practical considerations (sources of funding and logistical realities). We also envisage gradual expansion of this registry to other ILDs beyond IPF. The relevant infrastructure for an ILD registry is 


\section{TABLE 1 Proposed data content for a global idiopathic pulmonary fibrosis (IPF) registry}

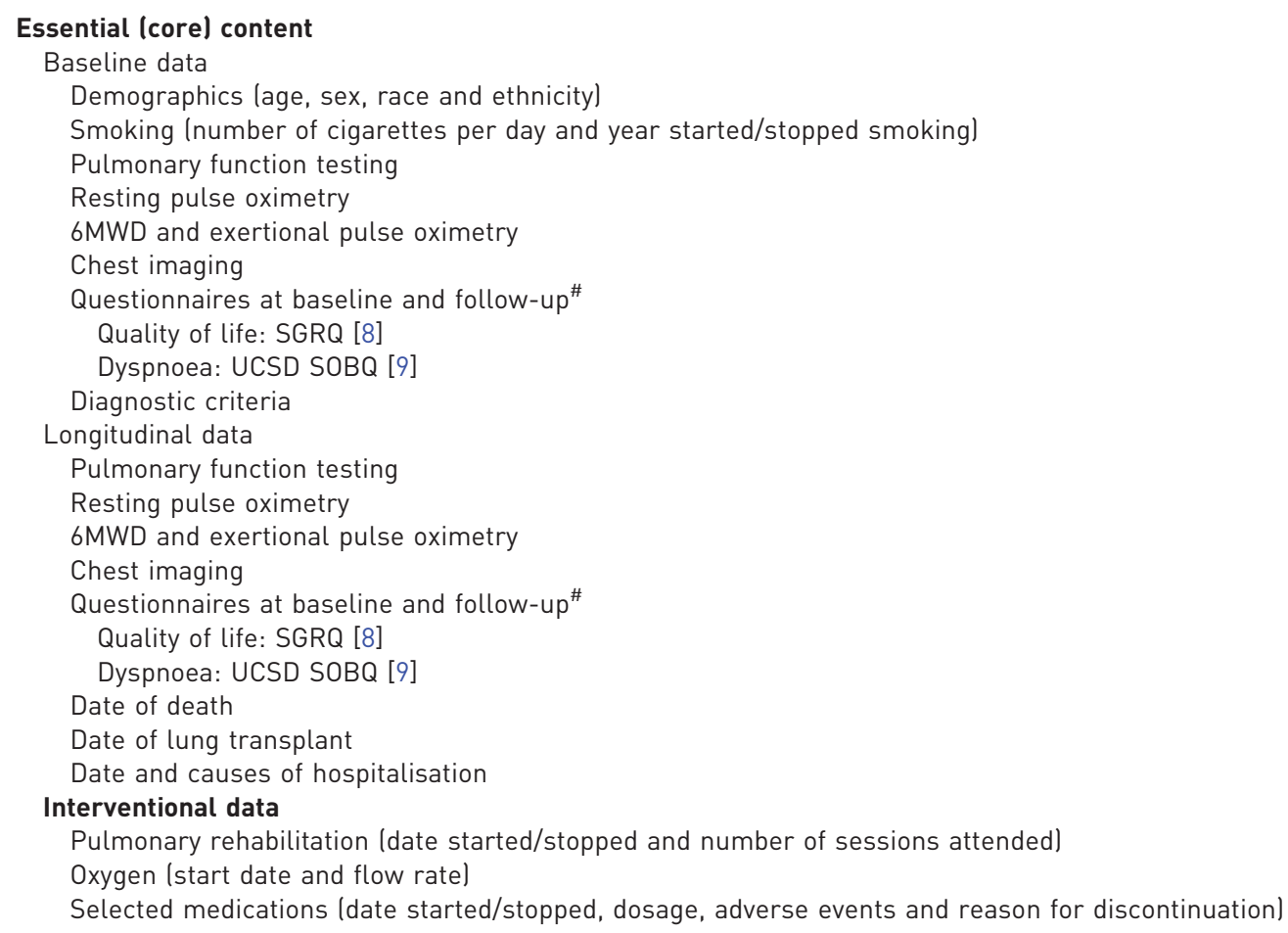

6MWD: 6-min walk distance; SGRQ: St George's Respiratory Questionnaire; UCSD SOBQ: University of California San Diego Shortness of Breath Questionnaire. " : the SGRQ and UCSD SOBQ are currently the best questionnaires for use in a prospective IPF registry [8,9], although future studies may support disease-specific instruments or other alternatives. This recommendation is based on their ease of administration, their frequent use in IPF trials and initial studies that suggest adequate performance characteristics of these questionnaires in IPF [10-12].

included in the framework above, and the impact of a global IPF registry could be significantly enhanced by such an expansion.

\section{Conclusion}

We strongly believe that the time is right to develop a global IPF registry. Such a registry would fundamentally reshape the research landscape and provide unprecedented opportunity for progress toward better understanding and, ultimately, a cure for this terrible disease. There is currently momentum for registry creation at the national level in multiple countries; we hope the framework detailed above will provide a practical and feasible template for the expansion of this effort to a global scale, and that the IPF community will rally behind the opportunity to make a global IPF registry a reality.

\section{Acknowledgements}

We would like to thank Juergen Behr (Ludwig-Maximilians University, Munich, Germany), Kevin K. Brown (National Jewish Health, Denver, CO, USA), Kevin R. Flaherty (University of Michigan Health System, Ann Arbor, MI, USA), Fernando J. Martinez (Weill Cornell Medical College, New York, NY, USA), Daniel M. Rose (Pulmonary Fibrosis Foundation, Chicago, IL, USA), Monica Spiteri (British Thoracic Society, London, UK) and Athol U. Wells (Royal Brompton and Harefield NHS Foundation Trust, London UK) for their thoughtful comments.

\section{References}

1 Raghu G, Collard HR, Egan JJ, et al. An official ATS/ERS/JRS/ALAT statement: idiopathic pulmonary fibrosis: evidence-based guidelines for diagnosis and management. Am J Respir Crit Care Med 2011; 183: 788-824.

2 Spagnolo P, du Bois RM, Cottin V. Rare lung disease and orphan drug development. Lancet Respir Med 2013; 1: 479-487.

3 Wuyts WA, Agostini C, Antoniou KM, et al. The pathogenesis of pulmonary fibrosis: a moving target. Eur Respir $J$ 2013; 41: 1207-1218.

4 Cordier JF, Cottin V. Neglected evidence in idiopathic pulmonary fibrosis: from history to earlier diagnosis. Eur Respir J 2013; 42: 916-923. 
5 Richeldi L, Collard HR, du Bois RM, et al. Mapping the future for pulmonary fibrosis: report from the 17th International Colloquium on Lung and Airway Fibrosis. Eur Respir J 2013; 42: 230-238.

6 Gliklich RE, Dreyer NA, eds. Registries for Evaluating Patient Outcomes: A User's Guide. 2nd Edn. Rockville, Agency for Healthcare Research and Quality, 2010.

7 Lederer DJ. Clinical trials in idiopathic pulmonary fibrosis: a framework for moving forward. Eur Respir J 2013; 42: 1446-1448.

8 Jones PW, Quirk FH, Baveystock CM. The St George's Respiratory Questionnaire. Respir Med 1991; 85: Suppl. B, 25-31.

9 Eakin EG, Resnikoff PM, Prewitt LM, et al. Validation of a new dyspnea measure: the UCSD Shortness of Breath Questionnaire. University of California, San Diego. Chest 1998; 113: 619-624.

10 Swigris JJ, Han M, Vij R, et al. The UCSD shortness of breath questionnaire has longitudinal construct validity in idiopathic pulmonary fibrosis. Respir Med 2012; 106: 1447-1455.

11 Swigris JJ, Brown KK, Behr J, et al. The SF-36 and SGRQ: validity and first look at minimum important differences in IPF. Respir Med 2010; 104: 296-304.

12 Yorke J, Jones PW, Swigris JJ. Development and validity testing of an IPF-specific version of the St George's Respiratory Questionnaire. Thorax 2010; 65: 921-926. 